\title{
Examining Nutritional Practices and Developmental Progress of Preschoolers
}

\author{
Barbara F. Hartigan, Joanna C. Macca \\ School of Education, University of Saint Joseph, West Hartford, USA \\ Email: bhartigan@usj.edu
}

Received 22 February 2015; accepted 12 March 2015; published 16 March 2015

Copyright (C) 2015 by authors and Scientific Research Publishing Inc.

This work is licensed under the Creative Commons Attribution International License (CC BY). http://creativecommons.org/licenses/by/4.0/

(c) (i) Open Access

\section{Abstract}

This teacher research was conducted to examine how nutrition is related to the developmental progress of preschool children. A quantitative correlational design was undertaken using researcher administered student, parent and teacher questionnaires to determine the strength of the relationship between healthy eating habits and achievement of appropriate developmental milestones of preschool children. Six students, who were four and five years old, were chosen to participate based on parental consent, researcher observation, and teacher recommendation. Three males and females were selected with varying racial backgrounds. Students completed an activity-based literacy assessment of knowledge about nutrition and "what it means to be healthy." Parents and teachers completed a survey discussing the children's eating habits. Teachers also completed a developmental checklist for four- and five-year-olds for each student. Students were then ranked by three different categories: knowledge of nutrition; personal health; and development. Results of the study were inconclusive; however, slight correlations were seen.

\section{Keywords}

Nutrition, Preschool, Developmental Milestones, Personal Health

\section{Introduction}

"The physical and emotional health of an entire generation and the economic health and security of our nation is at stake." (Obama, 2010).

The First Lady Michelle Obama first introduced her Healthier US School Challenge and Let's Move initiative in February of 2010. Her personal campaign to eliminate childhood obesity in one generation spurred President Obama to sign a Presidential Memorandum and create The Task Force on Childhood Obesity (TFCO). The TFCO (2010) states that combining healthy food choices and physical activity are the best ways to address 
the childhood obesity epidemic. There are five main goals as established by the TFCO which will aide in the reduction of obesity, and specifically childhood obesity. There are: 1) getting children a healthy start on life; 2) empowering parents and caregivers; 3) providing healthy foods in schools; 4) improving access to healthy, affordable foods; and 5) getting children more physically active (Task Force on Childhood Obesity, 2010). While First Lady Obama's work is aimed at the physical and emotional health of our children and the health and security of our nation, a direct result of her efforts is increased academic success.

Brown \& Pollitt (1996) examined the relationship between childhood nutrition and academic achievement. The Guatemalan Project (p. 40) examined children from Guatemala who received nutritional supplements in infancy. The influence of early diet and poverty on later intellectual development showed that children who had more than two years of formal education, and consuming nutritious supplements outperformed their peers on a battery of cognitive vocabulary tests. The nutritional supplements were seen as the social equalizer, helping children from low-income families achieve at the same level as their slightly more economically advantaged peers within the village (p. 41).

With recent national initiatives highlighting the importance of healthy eating habits of young Americans, parents and caretakers of young children strive to provide adequate nutrition for their youngsters. Petersen \& Wittmer (2013) state: "Families and teachers must be partners in following the nutritional recommendations of the pediatricians and health care professionals and providing opportunities to increase physical fitness" (p. 40). Additionally, the National Association for the Education of Young Children (NAEYC) Program Standard 5: Health asks that: "The Program [school] promotes the nutrition and health of children and protects children and staff from illness and injury (NAEYC, 2007: p. 10). Numerous studies (Lynn, 2009; McDermott, Durkin, Schupt, \& Stein, 2007; Ricciuti, 1993 in McDevitt \& Ormrod, 2013) indicate that severe malnutrition for extended periods of time in the early childhood years can impede neurological development which further impacts cognitive development. Sousa (2011) states:

Brain cells consume oxygen and glucose... for fuel. The more challenging the brain's task, the more fuel it consumes. Therefore, it is important to have adequate amounts of these substances in the brain for optimum functioning... Eating a moderate portion of food containing glucose... can boost the performance and accuracy of working memory, attention, and motor function (Korol \& Gold, 1998; Scholey, Moss, Neave, \& Wesnes, 1999 in Sousa, pp. 23-24).

Sousa continues by suggesting that schools have programs to educate students on the need to maintain adequate glucose levels throughout the school day. Students and staff should drink an eight-ounce glass of water for every twenty-five pounds of body weight frequently during the school day (Sousa, 2011). Nutrition is, after all, the foundation of many aspects of healthy living, and when good habits are formed at a young age through formal and informal instruction, there is a better chance for these practices to continue further on in life.

There is much debate about what exactly it means to have a healthy diet, as it is easy to exceed or underestimate the amount of nutrients the developing body requires (Sadowska, Radziszewska, \& Krzymuska, 2010). There are also many factors that contribute to an overall healthy lifestyle, such as, amount of exercise, dietary restrictions, daily schedules, and portion control. These can be extremely difficult elements to monitor as a parent, guardian, or educator of preschool-aged children, as it can be difficult to maintain a regimented exercise, hydration, and eating plan throughout a busy day. Arce (2008) suggests in Curriculum for Young Children that preschool-aged children should experience a wide variety of culturally diverse foods as this is a part of children's emergent learning. She proposes that children's experiences with nutritious foods should be a relevant and familiar focus of the curriculum, and that nutrition education helps young children, and their families, gain knowledge about food preparation, ethnicity, and benefits. While a healthy diet differs from culture to culture, expanding young children's nutritional awareness is key to physical and cognitive development.

Through all of the challenges that are associated with practicing a healthy lifestyle for preschool-aged children, it has been stated that one's growing body requires adequate nutrition to properly develop cognitively and behaviorally (Rosales, Reznick, \& Zeisel, 2009). Nutrition can be defined as resources from the environment (food and water) that can modify gene structure and regulate genetic factors by providing the specific molecules to exert potential to effect brain growth and development (Rosales, Reznick, \& Zeisel, 2009). In addition, nutrition has been determined to affect growth, as various vitamins and minerals that are consumed through food and beverage stimulate different bodily systems and functions that may be modified based on the amount of nutrients absorbed (Rosales, Reznick, \& Zeisel, 2009). 
The teacher researchers in this study attempted to answer the research question: Is there a correlation between preschoolers' nutritional knowledge (as assessed through literacy skills), healthy nutritional habits, and developmental progress, as assessed by their parents, preschool teachers, and teacher researchers?

\section{Methods}

This study was performed at a private preschool in West Hartford, Connecticut, during the spring semester of 2014. Six students were chosen and permitted to participate throughout the course of this research. Three were male, while three were female. Four students were Caucasian, one was African-American, and one was Asian. Children were four or five years old, but all participants were within five months of age.

Parents were asked to complete a brief survey, discussing how they would describe their child's eating habits, their child's favorite restaurants, participation in physical activities, concerns for their child's health, and a typical day of meals for their child. This form was utilized to determine a child's overall health and wellness for the purpose of this study.

In addition, the teacher researcher conducted a literacy play-based assessment, where students, in pairs, were required to sort pictures of food into "healthy" or "sometimes" food categories. They were then asked to pick some foods they liked to eat, foods they did not like to eat, and foods they have never heard of or tried before. Participants were also asked what "healthy" means and required to provide their own interpretation. The teacher researcher then read the picture book, Gregory, the Terrible Eater by Mitchell Sharmat (1980) to each group and asked interactive questions to further determine overall knowledge of nutrition and health. For reasons beyond the teacher researcher's control, two participants were unable to complete this portion of the study.

Teachers at the preschool completed a developmental checklist for four and five year olds, adapted from First Look and The Early Childhood Direction Center (2006) to determine milestones each participant had overcome and had yet to achieve. Teachers were also asked to complete a brief personal survey about their opinions in regards to development and nutrition for this specific age group. Of the fifteen teachers at this school, twelve surveys were returned.

After all of the forms were returned and research was completed, scores were compiled and compared in three different categories: nutritional knowledge, personal health, and overall development. Each participant was given a score based on the literacy play-based assessment of nutritional knowledge, parent survey discussing personal health, and developmental checklist completed by each child's teacher. Participants were then ranked from highest to lowest in each category to determine if there was a correlation among any of the categories.

\section{Results}

The results of this study are inconclusive. For some individual participants, there were correlations between two of the areas tested, but no individual had a significant correlation among all three matters. The scoring for each assessment was consistent and followed a predetermined rubric for the awarding and removal of points (Table 1 and Figure 1). After reviewing all participants'scores for each area, they were ranked in order of highest awarded scores to lowest awarded scores when compared to their fellow participants (Table 2). In addition, participants were evaluated individually to determine if there was any specific correlation for specific individuals, once it was determined there was no overarching correlation for all of the participants (Table 3).

Two of the six participants (Nicole C. \& Linda M.) displayed a slight correlation between their knowledge of nutrition and development. Linda $\mathrm{M}$. received a perfect score on her developmental assessment and correctly answered 24 out of 25 questions about what she knew in regards to nutrition (Table 1). Nicole C. also received relatively high scores in these areas, with a 22 out of 25 in knowledge of nutrition and 30 out of 33 in development (Table 1). Both Nicole C. and Linda M. scored significantly lower in the area of healthy practices. After reviewing the results from these two participants, it could be concluded that there is a potential correlation between how much a preschool-aged child knows about nutrition and their development.

Kim B's results indicated a correlation between knowledge of nutrition and healthy practices (Table 1). Her results indicated a score of 14 out of 25 on knowledge and 8 out of 15 on healthy practices. Out of the other participants, she was also ranked third for knowledge and fourth for healthy practices (Table 2 \& Table 3). Kim was also ranked third for development, though her score was significantly higher, as she received a 32 out of 33 in this area (Table 1 \& Table 3). After reviewing the results of Kim B's assessments, it is possible that knowledge of nutrition and healthy practices are correlated, but there was no relation to child development. 
Table 1. Scores awarded for each assessment.

\begin{tabular}{cccc}
\hline Participants & Knowledge of Nutrition Using Literacy Skills & Healthy Practices & Development \\
\hline Ryan B. & $11 / 25$ & $11 / 15$ & $31 / 33$ \\
Kim B. & $14 / 25$ & $8 / 15$ & $32 / 33$ \\
Nicole C. & $22 / 25$ & $11 / 15$ & $30 / 33$ \\
Aiden F. & 0 & $5 / 15$ & $12 / 33$ \\
Ron L. & 0 & $12 / 15$ & $33 / 33$ \\
Linda M. & $24 / 25$ & $10 / 15$ & $33 / 33$ \\
\hline
\end{tabular}

Table 2. Rankings of participants for each area of study.

\begin{tabular}{cccc}
\hline $\begin{array}{c}\text { Ranking } \\
\text { (1 is the highest score for each area) }\end{array}$ & $\begin{array}{c}\text { Knowledge of Nutrition Using } \\
\text { Literacy Skills }\end{array}$ & Healthy Practices & Development \\
\hline $\mathbf{1}$ & Linda M. & Ron L. & Ron L./Linda M. \\
$\mathbf{2}$ & Nicole C. & Ryan B./Nicole C. & Kim B. \\
$\mathbf{3}$ & Kim B. & Linda M. & Ryan B. \\
$\mathbf{4}$ & Ryan B. & Kim B. & Nicole C. \\
$\mathbf{6}$ & & Aiden F. & Aiden F. \\
\hline
\end{tabular}

Table 3. Participants' rankings for each area (1 is the highest).

\begin{tabular}{cccc}
\hline Participants & Knowledge of Nutrition Using Literacy Skills & Healthy Practices & Development \\
\hline Ryan B. & 4 & 2 & 3 \\
Kim B. & 3 & 4 & 3 \\
Nicole C. & 2 & 2 & 4 \\
Aiden F. & & 5 & 5 \\
Ron L. & 1 & 1 & 1 \\
Linda M. & 1 & 3 & 1 \\
\hline
\end{tabular}

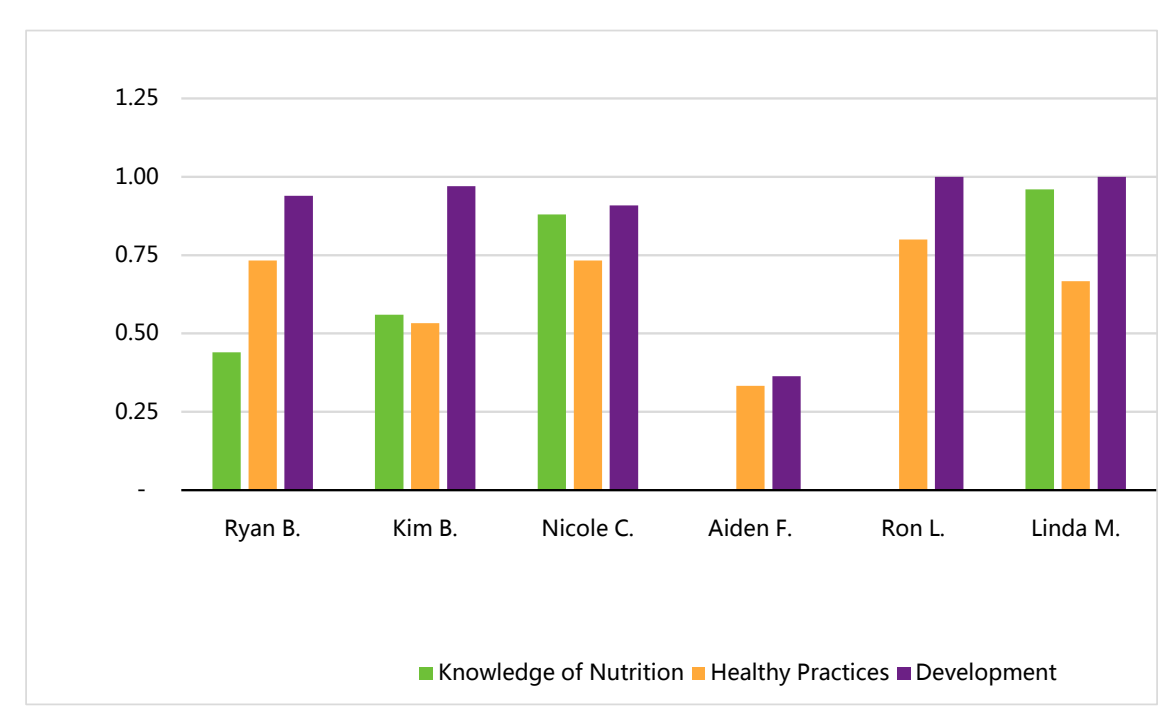

Figure 1. Score percentages for each area. 
Though Aiden F. and Ron L. were unable to complete the knowledge of nutrition assessment, their results on healthy practices and development demonstrated a correlation. Aiden F. ranked fifth for both areas, as he received the lowest scores of the six participants (Table 2 \& Table 3). Aiden scored 5 out of 15 on the healthy practices assessment and 12 out of 33 for development (Table 1). Ron L. received a perfect score on the developmental assessment, which ranked him tied for first with Linda M. when compared to the other participants (Tables 1-3). He also received a score of 12 out of 15 on the healthy practices, which was also the highest score earned among the participants (Table 1). These individual results indicate a correlation between low health practices and low developmental levels among this age group, as well as high health practices and high developmental levels.

After reviewing the data on Ryan B., there was no significant correlation among any of the areas that were assessed. Ryan was ranked fourth for knowledge of nutrition, second for healthy practices, and third for development (Table 3). In addition, his individual results on each assessment ranged from receiving scores of 44 percent on knowledge to 94 percent on development, with a healthy practices score of 73 percent falling in the middle (Figure 1). With such a wide range of results, it can be concluded that there is no correlation among any of the areas for Ryan B's results.

\section{Discussion}

Throughout the execution of this teacher research, there were several factors that could have contributed to the overall outcome. Firstly, two students were unable to complete the knowledge of nutrition assessment for reasons out of the control of the researcher. These were the two students who demonstrated a correlation in the other two areas. If given the opportunity to complete the third assessment with these specific participants, results would have been more accurate and a better conclusion on the overall outcomes could potentially have been determined.

In addition, these assessments were administered during the participants'choice play time at their preschool program. It is possible that students were rushing through the knowledge of nutrition assessment in order to return to their peers, which would make the current results inaccurate. Teachers were also completing their developmental checklists at this time, so it is possible they were distracted and failed to complete assessments in an accurate manner. To increase the validity of these assessments, it could be possible to complete different activities and ways to assess the same material, but present it in a variety of ways.

The developmental checklists that were completed by the teachers of the participants could also be viewed as very subjective. There were different teachers filling out each assessment and depending on personal views, knowledge of the child, and the amount of interaction that occurs between each participant and the teacher, the results could vary. With an increased time allotment, consistent activities could be performed and observed to determine the exact development of the participants.

The health habits of the participants were measured based on a parent survey that went home with students and was returned to the school within a week. It is very possible that these surveys did not display accurate results, as parents could have feared being judged for their child's eating habits, or were also distracted at the time they were completed. With these criteria in mind, perhaps more extensive research could be completed to determine what each participant consumed on a day-to-day basis and the amount of physical activity that occurred each week as well.

Lastly, students were ranked based on a scoring system to determine if there was a correlation among the three areas of study. Though these methods were consistent and scores were awarded based on a specific rubric and scoring process, there was still the possibility for human error and subjective decisions. To improve this aspect of the research, perhaps participants could be placed into percentiles and compared through a standardized method, as this would decrease the potential for subjective decisions, increase accuracy, and increase consistency when reviewing scores and results from each area of the research.

\section{Conclusion}

The overall results of this research remain inconclusive. Two out of six participants demonstrated a correlation between knowledge of nutrition and development, with no correlation to healthy practices. Two other participants displayed a correlation between healthy practices and development. One individual participant displayed results indicating an association between knowledge of nutrition and healthy practices and the remaining participant did 
not demonstrate any correlation among the three areas of the research. Though there has been significant research performed in regards to this topic, further investigation is required to determine definite results.

Upon completion of the aforementioned research, a unit of study discussing nutrition was designed and taught at the same site previously stated. The unit included lesson plans and materials for ten days of literacy instruction and include a pre, mid, and post assessment to provide further comprehension and information in regards to nutrition in preschool. Teachers were provided with a completed copy of the unit of study for their own reference and data. It would be interesting to follow these students and further document their healthy nutritional choices throughout their educational careers.

A teacher researcher was also provided the opportunity to teach a lesson from the aforementioned unit to the participants of the study, as well as any willing students in the classroom. Students were taught about proper eating habits and what types of foods should be eaten at every meal. Students were also taught about portion control and the ratio of food groups that should be eaten at every meal. Each participant was given the opportunity to create a "healthy plate" filled with proper foods in the grains, vegetable, fruit, and protein food groups.

Through this experience, all participants were exposed to more information about healthy eating. It is possible that after the completion of this study, and through participation in the lesson, students will attempt to make healthier eating choices or share the information they learned with peers or family members. In addition, the educators of this preschool program were provided with resources to continue the efforts of these teacher researchers and further the exploration into diet and nutrition. With these comprehensive and interactive resources, both students and teachers can further grow and develop as healthy individuals.

These teacher researchers believe student knowledge about proper nutrition and exercise is a vital component of all early childhood educational environment. Parents and educators alike should model and teach healthy lifestyle choices to all students on a continuous basis so that proper cognitive and physical development can take place (Kostelnik, Rupiper, Soderman, \& Whiren, 2014).

\section{References}

Arce, E. M. (2008). Curriculum for Young Children (2nd ed.). Belmont, CA: Cengage.

Brown, J. L., \& Pollitt, E. (1996). Malnutrition, Poverty and Intellectual Development. Scientific American, February, 38-43.

Kostelnik, M. J., Rupiper, M., Soderman, A. K., \& Whiren, A. P. (2014). Developmentally Appropriate Curriculum in Action. Upper Saddle River, NJ: Pearson.

McDevitt, T. M., \& Ormrod, J. E. (2013). Child Development and Education (5th ed.). Upper Saddle River, NJ: Pearson.

NAEYC (2007). NAEYC Early Childhood Program Standards and Accreditation Criteria: The Mark of Quality in Early Childhood Education. Washington, DC: NAEYC.

Obama, M. (2010). Let's Move. http://www.letsmove.gov

Petersen, S. H., \& Wittmer, D. S. (2013). Endless Opportunities for Infant and Toddler Curriculum: A Relationship-Based Approach (2nd ed.). Upper Saddle River, NJ: Pearson.

Rosales, F., Reznick, S., \& Zeisel, S. (2009). Understanding the Role of Nutrition in the Brain and Behavioral Development of Toddlers and Preschool Children: Identifying and Addressing Methodological Barriers. Nutritional Neuroscience, 12, 190-202. http://dx.doi.org/10.1179/147683009X423454

Sadowska, J., Radziszewska, M., \& Krzymuska, A. (2010). Evaluation of Nutrition Manner and Nutritional Status of Pre-School Children. ACTA Scientiarum Polonorum, 9, 105-115.

Sharmat, M. (1980). Gregory, the Terrible Eater. New York: Scholastic, Inc.

Sousa, D. A. (2011). How the Brain Learns (4th ed.). Thousand Oaks, CA: Corwin.

The Early Childhood Direction Center (2006). Developmental Checklists Birth to Five. http://www.preschoollearningcenter.org/images/upload/developmental_checklist.pdf

White House Task Force on Childhood Obesity. (2010). http://www.letsmove.gov/sites/letsmove.gov/files/TaskForce on Childhood Obesity May2010 FullReport.pdf 